\title{
DIRECT ABSORPTION METHOD AND LIQUID SCINTILLATION COUNTING FOR RADIOCARBON MEASUREMENTS IN ORGANIC CARBON FROM SEDIMENTS
}

\author{
Ionut Faurescu ${ }^{1,2} \cdot$ Carmen Varlam $^{1} \cdot$ Ioan Stefanescu $^{1} \cdot$ Stela Cuna $^{3} \bullet$ Irina Vagner $^{1} \bullet$ \\ Denisa Faurescu ${ }^{1}$ Diana Bogdan ${ }^{1}$
}

\begin{abstract}
In this paper, we investigate a procedure for radiocarbon determination in forest soil and slurry from lake sediments. The total carbon in these samples can be both inorganic and organic. Inorganic carbon can be analyzed in a straightforward manner using the direct absorption method by sample acidification and $\mathrm{CO}_{2}$ capture. For organic carbon, we investigate a hybrid method using the wet-oxidation of organic carbon followed by direct absorption. To evaluate the wet-oxidation processes with potassium dichromate $\left(\mathrm{K}_{2} \mathrm{Cr}_{2} \mathrm{O}_{7}\right)$ and potassium permanganate $\left(\mathrm{KMnO}_{4}\right)$, we performed several experiments using different quantities of soil and sediments in order to establish the quantity of $\mathrm{CO}_{2}$ for each type of sample. The 2 methods offer comparable results for ${ }^{14} \mathrm{C}$-specific activity (about $0.234 \pm 0.024 \mathrm{~Bq} / \mathrm{g} \mathrm{C}$ ), values that are expected for these kinds of samples. We also investigated the possibility of isotopic fractionation occurring during $\mathrm{CO}_{2}$ production from raw material by measuring $\delta^{13} \mathrm{C}$ levels from samples and obtained $\mathrm{CO}_{2}$.
\end{abstract}

\section{INTRODUCTION}

Organic matter originates from the biological activity of plants and animals, both in and on the soil. Furthermore, organic matter conditions determine the way biological activity evolves, acting at 3 main levels: (1) in the case of clay, storing water and nutrients, thus enhancing the soil's water-holding capacity; (2) maintaining the soil's structural stability by clumping mineral particles together into aggregates and thereby contributing to soil permeability; and (3) promoting biological and microbial activity that renders mineral matter suitable for uptake by plants (Magny and Baur 1962; Mathur 1991).

Considering these effects on the physical and chemical properties of soils, the organic matter content of the surface layer is an indicator of soil fertility and structural stability. In a natural situation, the radiocarbon concentrations of various carbon-containing reservoirs on Earth are in steady-state. Of course, depending on their interaction with atmospheric $\mathrm{CO}_{2}$, these steady-state values vary from being equal to atmospheric ${ }^{14} \mathrm{C}$ concentration (leaves, young plant material, surface layer soil), down to being virtually zero (ocean sediments, fossil fuel). By measuring the organic carbon ${ }^{14} \mathrm{C}$ activity in soil, it can be determined whether the organic matter is influenced by anthropogenic $\mathrm{CO}_{2}$ or by synthetic organics, such as pesticides used in agriculture.

Nuclear power plants release ${ }^{14} \mathrm{C}$ during routine operations, mainly as gaseous effluents. The amounts of chemical forms released * such as hydrocarbons, $\mathrm{CO}$, and $\mathrm{CO}_{2}$ ) depend on the individual reactor design as well as operational parameters. For example, CANDU (CANada Deuterium Uranium) reactors are known to be the worst emitters (UNSCEAR 2000), while PWR (pressurized water reactors) release minor amounts of ${ }^{14} \mathrm{C}$, mainly as hydrocarbons. Today, fossil fuels are burned on large scales, forest areas are converted to grasslands and vice versa, deserts are increasing in size, and nutrients on land and in coastal seas are more widely available as a result of fertilizer products. The effects of these processes, combined with the release of anthropogenic ${ }^{14} \mathrm{C}$ from nuclear power plants, are significant enough to warrant wide-ranging monitoring programs in order to evaluate potentially negative impacts on the ecosystem.

\footnotetext{
${ }^{1}$ Institute for Cryogenics and Isotopic Technologies, Rm. Valcea, Romania.

${ }^{2}$ Corresponding author. Email: ifaurescu@icsi.ro.

${ }^{3}$ Institute for Isotopic and Molecular Technologies, Cluj-Napoca, Romania.
}

(c) 2010 by the Arizona Board of Regents on behalf of the University of Arizona Proceedings of the 20th International Radiocarbon Conference, edited by A J T Jull RADIOCARBON, Vol 52, $\mathrm{Nr}$ 2-3, 2010, p 794-799 
The Romanian nuclear power plant Cernavoda has 2 CANDU nuclear reactors, and is the only nuclear power plant in Europe with CANDU reactors. This nuclear power plant does generate some disturbance in the environment, warranting the continuous monitoring of soil, air, and water.

The radionuclide ${ }^{14} \mathrm{C}$ is a byproduct of nuclear power plants that results primarily from neutron activation of ${ }^{17} \mathrm{O}$ from heavy-water molecules, heavy water being used as a moderator in CANDU units. ${ }^{14} \mathrm{C}$ enters the natural circuit as $\mathrm{CO}_{2}$, and is found in water, air, soil, and sediments around the nuclear power plants. Since more stringent environmental regulation can be expected in the future due to the installation of new operating units, specific studies of ${ }^{14} \mathrm{C}$ from soil, water, and air around the facilities and their impact on the environment are likely to be required.

In soils and sediments, 3 basic forms of carbon may be present: (1) elemental carbon; (2) inorganic carbon; and (3) organic carbon. The quality of organic matter in sediments is critical to the partitioning and bioavailability of sediment-associated contaminants. Naturally occurring organic carbon forms are derived from the decomposition of plants and animals. In soils and sediments, a wide variety of organic carbon forms are present and range from freshly deposited litter (e.g. leaves, twigs, branches) to highly decomposed forms such as humus (Schumacher 2002).

For sample preparation, oxidation of organic matter from the soils followed by capture of $\mathrm{CO}_{2}$ can be achieved using the following methods, each performed following the removal of carbonates from the sample: (1) dry combustion; (2) wet-oxidation using potassium dichromate; (3) wet-oxidation using potassium permanganate; and (4) wet-oxidation using hydrogen peroxide and a proper catalyst.

The dry combustion methods that directly measure evolved $\mathrm{CO}_{2}$ require special apparatus and are not well adapted for the rapid analysis of a large number of samples unless rather expensive automated and computerized carbon analyzers are used. Consequently, the wet-oxidation methods that employ potassium dichromate or potassium permanganate to determine easily oxidizable material are those most commonly used by soil testing laboratories. The wet-oxidation method using hydrogen peroxide is a semi-quantitative method, with some limitations regarding the nature of organic matter, the heating of the sample, and the formation of molecular oxygen that must be removed in order to obtain $\mathrm{CO}_{2}$ in as pure a form as possible.

Over the last decade, the $\mathrm{CO}_{2}$ direct absorption method for preparing samples for ${ }^{14} \mathrm{C}$ analysis by liquid scintillation counting (LSC) has been successfully employed in many laboratories, mainly for dating groundwater. The method was developed for commercial scale-up in our own laboratory (Varlam et al. 2007) and follows the measurement procedure developed by SCIRO Land and Water (Vita-Finzi and Leaney 2006). That method involves capturing the $\mathrm{CO}_{2}$ obtained from oxidation of the organic carbon of soil and sediment samples in a suitable liquid scintillation cocktail of our own making, and measuring the ${ }^{14} \mathrm{C}$ activity by LSC.

We chose to further investigate wet-oxidation methods for soil and sediment samples using potassium dichromate and potassium permanganate, as they are considered quite accurate, require minimal time, and are relatively inexpensive to perform. The $\mathrm{CO}_{2}$ obtained from wet-oxidation was captured using the direct absorption method in a liquid scintillation cocktail, and ${ }^{14} \mathrm{C}$ activity measured.

\section{METHODS, EQUIPMENT, AND MATERIALS}

The direct absorption method involves ${ }^{14} \mathrm{C}$ measurement through direct absorption of $\mathrm{CO}_{2}$ into a scintillation cocktail, following similar principles to those used in benzene synthesis. The basic principle involves measuring ${ }^{14} \mathrm{C}$ contained in a known quantity of carbon obtained from the soil or sediment samples and background (marble), as liquid, using liquid scintillation counting (Varlam et al. 
2007). The difference between the 2 methods is the way that carbon from the samples or background is converted into a liquid form before LSC measurement.

The methods tested in our laboratory were wet-oxidation of the soil and samples, using 2 oxidizing agents: potassium dichromate $\left(\mathrm{K}_{2} \mathrm{Cr}_{2} \mathrm{O}_{7}\right)$ and potassium permanganate $\left(\mathrm{KMnO}_{4}\right)$. The soil and sediment samples were initially dried in an oven at $60{ }^{\circ} \mathrm{C}$, then milled and sieved until dimensions of the particles were less than $250 \mu \mathrm{m}$. The $\mathrm{CO}_{2}$ resulting from oxidation was captured in a homemade liquid scintillation cocktail.

The wet-oxidation method using potassium dichromate requires the use of $1 \mathrm{~L}$ of solution of $1 \mathrm{~N}$ $\mathrm{K}_{2} \mathrm{Cr}_{2} \mathrm{O}_{7}$, sulfuric acid, and silver sulfate. The dried soil and sediment samples were oxidized by first adding the sulfuric acid and silver sulfate to remove inorganic carbon that might be present as carbonates. After adding the potassium dichromate solution, the sample was heated at $90-110^{\circ} \mathrm{C}$ to release the gaseous $\mathrm{CO}_{2}$, a process that produced some water vapors that required removal by condensation. The resulting gas was then captured using the cryogenic technique in a cylinder and directly absorbed into the liquid scintillation cocktail.

The wet-oxidation method using potassium permanganate requires the use of a 1 - $\mathrm{L}$ solution $4 \%$ and is similar to the process given above for potassium dichromate. A method described by Varlam et al. (2007) was applied to obtain $\mathrm{CO}_{2}$ from background carbonate material (marble). This process involves the acidification of marble with release of $\mathrm{CO}_{2}$ that is purified, bubbled, and captured in the liquid scintillation cocktail as carbamate. Otherwise, the only difference between these 2 wet-oxidation methods is that oxidation with potassium permanganate can take place without heating, at room temperature. This difference can be a considerable advantage, as there are no resulting water vapors that must be condensed in order to achieve cryogenic purification of the obtained $\mathrm{CO}_{2}$.

The $\mathrm{CO}_{2}$ obtained was captured using the same cryogenic line as in the commercial method applied for inorganic carbon from waters (Varlam et al. 2007) and stored for 3 weeks. During this time, any radon present in the obtained $\mathrm{CO}_{2}$ will have decayed. The next step was to bubble the obtained $\mathrm{CO}_{2}$ in a liquid scintillation cocktail and capture it as carbamate. Samples were measured by LSC, using a Quantulus $1220^{\mathrm{TM}}$ mass spectrometer from LKB-Wallac Oy (Varlam et al. 2007).

To determine the ${ }^{14} \mathrm{C}$ activity of the $\mathrm{CO}_{2}$ retained as carbamate, the quantity of the organic carbon as $\mathrm{CO}_{2}$ was established. For that, a known quantity (by weight) of liquid scintillation cocktail was used in the bubbling line and, after retaining the $\mathrm{CO}_{2}$, the liquid scintillation cocktail was weighed again. The difference between the initial and the final weight of the cocktail was determined as the mass of $\mathrm{CO}_{2}$ retained as carbamate.

Due to the low-level radioactivity expected, we chose to use internal standards to establish counting efficiency. The standard sample used for the measurement of ${ }^{14} \mathrm{C}$ activity from the obtained organic carbon was prepared from a sample of $\mathrm{CO}_{2}$ identical to the one used for ${ }^{14} \mathrm{C}$ measurement. A standard capsule, originating from an internal standard kit for LSC and containing 103,000 dpm/capsule (Wallac, product No. 1210-122, reference date January 2009) was dissolved. The labeled compound, $\left[4-{ }^{14} \mathrm{C}\right]$ - cholesterol is produced by Amersham International, UK. The absolute activity of the capsules is calibrated by comparison with reference standards of $\left[1-{ }^{14} \mathrm{C}\right]-\mathrm{n}$ - hexadecane supplied by NIST (SRM No. 4222C). For each batch, the quench of prepared samples was checked using the spectral quench parameter of the external standard, SQP(E).

The methods used to obtain organic carbon from soil and sediment samples had to be verified to determine if isotopic fractionation took place during the wet-oxidation process. Thus, $\delta^{13} \mathrm{C}$ was measured in both the obtained $\mathrm{CO}_{2}$ from the wet-oxidations and also in the soil or sediment samples. 
The ${ }^{13} \mathrm{C} /{ }^{12} \mathrm{C}$ ratio was measured by mass spectrometry from small aliquots of $\mathrm{CO}_{2}$ gas. Values are given relative to the VPDB standard, with the overall precision typically being $\pm 0.2 \%$.

\section{RESULTS}

To evaluate the wet-oxidation processes with potassium dichromate $\left(\mathrm{K}_{2} \mathrm{Cr}_{2} \mathrm{O}_{7}\right)$ and potassium permanganate $\left(\mathrm{KMnO}_{4}\right)$, we performed several experiments using different quantities of soil and sediments in order to establish the quantity of $\mathrm{CO}_{2}$ for each type of sample. Samples numbered 1 to 5 were divided into 5 parallels from a large amount of forest soil and sediment. Soil and sediment samples were dried at $60^{\circ} \mathrm{C}$ until they reached a constant mass. This temperature was chosen to prevent any loss of organic matter that might occur at elevated temperatures (Schumacher 2002).

After the wet-oxidation of the organic carbon from dried samples, the $\mathrm{CO}_{2}$ evolved was captured in $20 \mathrm{~mL}$ of liquid scintillation cocktail. The difference measured between the mass of the cocktail before and after was used to determine the mass of $\mathrm{CO}_{2}$ captured (Table 1).

Table 1 Amount of $\mathrm{CO}_{2}$ captured in the liquid scintillation cocktail as carbamate, from different samples, using $\mathrm{K}_{2} \mathrm{Cr}_{2} \mathrm{O}_{7}$ wet-oxidation and $\mathrm{KMnO}_{4}$ wet-oxidation.

\begin{tabular}{llll|lll}
\hline & \multicolumn{3}{c|}{$\mathrm{CO}_{2}$ captured using $\mathrm{K}_{2} \mathrm{Cr}_{2} \mathrm{O}_{7}$} & \multicolumn{3}{c}{$\mathrm{CO}_{2}$ captured using $\mathrm{KMnO}_{4} \mathrm{n}$} \\
\cline { 2 - 7 } Sample & $40 \mathrm{~g}$ sample & $60 \mathrm{~g}$ sample & $80 \mathrm{~g}$ sample & $40 \mathrm{~g}$ sample & $60 \mathrm{~g}$ sample & $80 \mathrm{~g}$ sample \\
\hline Forest soil 1 & $1.12 \pm 0.01$ & $2.25 \pm 0.01$ & $2.32 \pm 0.01$ & $1.17 \pm 0.01$ & $2.31 \pm 0.01$ & $2.32 \pm 0.01$ \\
Forest soil 2 & $1.14 \pm 0.01$ & $2.27 \pm 0.01$ & $2.32 \pm 0.01$ & $1.18 \pm 0.01$ & $2.33 \pm 0.01$ & $2.33 \pm 0.01$ \\
Forest soil 3 & $1.15 \pm 0.01$ & $2.29 \pm 0.01$ & $2.34 \pm 0.01$ & $1.18 \pm 0.01$ & $2.34 \pm 0.01$ & $2.34 \pm 0.01$ \\
Forest soil 4 & $1.12 \pm 0.01$ & $2.23 \pm 0.01$ & $2.32 \pm 0.01$ & $1.16 \pm 0.01$ & $2.30 \pm 0.01$ & $2.31 \pm 0.01$ \\
Forest soil 5 & $1.14 \pm 0.01$ & $2.27 \pm 0.01$ & $2.32 \pm 0.01$ & $1.17 \pm 0.01$ & $2.32 \pm 0.01$ & $2.32 \pm 0.01$ \\
Bottom sediments 1 & $1.02 \pm 0.01$ & $2.05 \pm 0.01$ & $2.31 \pm 0.01$ & $1.07 \pm 0.01$ & $2.13 \pm 0.01$ & $2.33 \pm 0.01$ \\
Bottom sediments 2 & $0.96 \pm 0.01$ & $1.93 \pm 0.01$ & $2.33 \pm 0.01$ & $0.99 \pm 0.01$ & $2.08 \pm 0.01$ & $2.29 \pm 0.01$ \\
Bottom sediments 3 & $0.99 \pm 0.01$ & $1.97 \pm 0.01$ & $2.30 \pm 0.01$ & $1.04 \pm 0.01$ & $2.09 \pm 0.01$ & $2.32 \pm 0.01$ \\
Bottom sediments 4 & $1.05 \pm 0.01$ & $2.11 \pm 0.01$ & $2.34 \pm 0.01$ & $1.08 \pm 0.01$ & $2.15 \pm 0.01$ & $2.34 \pm 0.01$ \\
Bottom sediments 5 & $0.97 \pm 0.01$ & $1.95 \pm 0.01$ & $2.32 \pm 0.01$ & $1.05 \pm 0.01$ & $2.09 \pm 0.01$ & $2.32 \pm 0.01$ \\
\hline
\end{tabular}

It can be noted that the weight of the captured $\mathrm{CO}_{2}$ is a function of the weight of the dried samples used in the oxidation process, until the scintillation cocktail is saturated with $\mathrm{CO}_{2}$. The saturation point is reached for forest soil samples at $\sim 80 \mathrm{~g}$ of sample when using potassium dichromate wetoxidation and 60-70 $\mathrm{g}$ weight when using potassium permanganate wet-oxidation. For bottom sediment samples, the saturation point of scintillation cocktail with $\mathrm{CO}_{2}$ was reached using $80 \mathrm{~g}$ of dried sample in both wet-oxidation processes.

${ }^{14} \mathrm{C}$ activity was measured by placing the saturated liquid scintillation cocktail in 20 -mL low-background glass vials with Teflon ${ }^{\circledR}$ inserts inside the caps, and by counting with the Quantulus 1220 spectrometer for $1000 \mathrm{~min}$. The values obtained for the potassium dichromate wet-oxidation process are presented in Table 2. The spectral quench parameter varied between 644.13 and 711.87 , proving that the prepared sample depreciated during measurement. In fact, after 1000 min of measurement, the prepared saturated cocktail samples became colored, ranging from light yellow to orange depending on the different gases present (hydrochloric acid, volatile organic compounds, sulfur dioxide, hydrogen sulfide, etc.). Without quench correction, the color influenced the final result calculations, resulting in different values for the same sample, and ranging between $0.177 \pm 0.018$ and $0.241 \pm 0.024 \mathrm{~Bq} / \mathrm{g} \mathrm{C}$. It should be noted that the surface layer can be in steady-state with the atmosphere and can be between 0.226 and $0.250 \mathrm{~Bq} / \mathrm{g} \mathrm{C}$ (IAEA 2004) without any concern from a radiological point of view. 
Table $2{ }^{14} \mathrm{C}$ specific activity using wet-oxidation with potassium dichromate solution, sulfuric acid, and silver nitrate and with potassium permanganate solution and sulfuric acid. ${ }^{\mathrm{a}}$

\begin{tabular}{|c|c|c|c|c|c|c|c|c|c|c|}
\hline \multirow[b]{2}{*}{ Sample } & \multirow[b]{2}{*}{$\begin{array}{l}{ }^{13} \delta_{\mathrm{PDB}} \\
{[\% \mathrm{o}]}\end{array}$} & \multirow[b]{2}{*}{$\begin{array}{l}\mathrm{CO}_{2}{ }^{13} \delta_{\mathrm{PDB}} \\
{[\% \mathrm{o}]}\end{array}$} & \multicolumn{4}{|c|}{$\mathrm{K}_{2} \mathrm{Cr}_{2} \mathrm{O}_{7}$ wet-oxidation } & \multicolumn{4}{|c|}{$\mathrm{KMnO}_{4}$ wet-oxidation } \\
\hline & & & $\begin{array}{l}\text { Eff. } \\
{[\%]}\end{array}$ & FOM & $\mathrm{SQP}(\mathrm{E})$ & $\begin{array}{l}{ }^{14} \mathrm{C} \text {-specific } \\
\text { activity } \\
{[\mathrm{Bq} / \mathrm{g} \mathrm{C}]}\end{array}$ & $\begin{array}{l}\text { Eff. } \\
{[\%]}\end{array}$ & FOM & $\mathrm{SQP}(\mathrm{E})$ & $\begin{array}{l}{ }^{14} \mathrm{C} \text {-specific } \\
\text { activity } \\
{[\mathrm{Bq} / \mathrm{g} \mathrm{C}]}\end{array}$ \\
\hline Forest soil 1 & $23.1 \pm 0.2$ & $22.9 \pm 0.2$ & & & 709.23 & $0.241 \pm 0.024$ & & & 711.16 & $0.244 \pm 0.024$ \\
\hline Fore & 23 & 2 & & & & & & & 0.44 & \\
\hline Fore & 22.9 & 23.2 & & & 711.87 & 0.24 & & & 708.85 & \\
\hline & & & & & & & & & & \\
\hline t soil 5 & & $23.0 \pm 0.2$ & 66.91 & 1938 & 712.01 & $0.231 \pm 0.023$ & 68.27 & 1994 & 711.12 & \\
\hline $\begin{array}{l}\text { Bottom } \\
\text { sediments } 1\end{array}$ & $21.2 \pm 0.2$ & $21.2 \pm 0.2$ & & & 707.84 & $0.229 \pm 0.022$ & & & 710.14 & 0.233 \\
\hline $\begin{array}{l}\text { Bottom } \\
\text { sediments } 2\end{array}$ & $21.1 \pm 0.2$ & $21.2 \pm 0.2$ & & & 644.13 & $0.145 \pm 0.015$ & & & 709.32 & $0.227 \pm 0.023$ \\
\hline $\begin{array}{l}\text { Bottom } \\
\text { sediments } 3\end{array}$ & $21.2 \pm 0.2$ & $21.0 \pm 0.2$ & & & 674.91 & 0.195 & & & 711.78 & $0.221 \pm 0.022$ \\
\hline $\begin{array}{l}\text { Bottom } \\
\text { sediments } 4\end{array}$ & $21.2 \pm 0.2$ & $21.1 \pm 0.2$ & & & 708.56 & $0.224 \pm 0.022$ & & & 714.17 & $0.219 \pm 0.021$ \\
\hline $\begin{array}{l}\text { Bottom } \\
\text { sediments } 5\end{array}$ & $21.2 \pm 0.2$ & $21.3 \pm 0.2$ & & & 710.14 & $0.232 \pm 0.023$ & & & 709.59 & $0.233 \pm 0.023$ \\
\hline
\end{tabular}

${ }^{\mathrm{a}}$ Eff. $=$ efficiency; FOM $=$ figure of merit; SQP(E) = spectral quench parameter of the external standard.

The same parameters and equipment were used for the second experiment. The $\mathrm{CO}_{2}$ was obtained by wet-oxidation with potassium permanganate solution and sulfuric acid was captured in $20 \mathrm{~g}$ of a custom-made liquid scintillation cocktail, transferred into $20-\mathrm{mL}$ low-background glass vials, and counted for 1000 min using a Quantulus 1220 spectrometer. The results are presented in Table 2. The efficiency of the measurement was higher than that obtained in the first experiment, having a value of $68.27 \%$. The spectral quench parameter $(\mathrm{SQP}(\mathrm{E}))$ has an average of 710.92 with a slight variation of less than $1 \%$, which is acceptable (Hemmila et al. 1994). The measured carbamate was clear, without any change in color despite the lengthy counting time. The average ${ }^{14} \mathrm{C}$-specific activity was $0.241 \pm 0.024$ and $0.227 \pm 0.023 \mathrm{~Bq} / \mathrm{g} \mathrm{C}$ for the forest soil and bottom sediments, respectively. The results are in the expected range, with the surface soil layer being in steady-state with atmosphere. The measured ${ }^{13} \delta_{\mathrm{PDB}}$ for the sample and the obtained $\mathrm{CO}_{2}$ are practically the same, given the measurement uncertainties.

\section{CONCLUSIONS}

Of the 2 wet-oxidation methods investigated, we find that the method using potassium permanganate is more effective because it can be performed at room temperature, and because the oxidation efficiency is higher than that of the potassium dichromate method. The amount of dried sample required to obtain the $\mathrm{CO}_{2}$ necessary to saturate $20 \mathrm{~mL}$ of liquid scintillation cocktail is a function of the type of wet-oxidation method used. For bottom sediment samples, using wet-oxidation both with potassium dichromate and potassium permanganate, the quantity needed is $\sim 80 \mathrm{~g}$ of dried sample. For forest soil samples, using potassium dichromate wet-oxidation, the necessary quantity is $80 \mathrm{~g}$, while using potassium permanganate wet-oxidation, the necessary quantity is between 60 and $70 \mathrm{~g}$ of dried sample.

The gaseous mixture resulting from the wet-oxidation of samples with potassium dichromate may contain different gases (hydrochloric acid, volatile organic compounds, sulfur dioxide, hydrogen sulfide, etc.) that are a function of the soil or sediment nature and source, and contribute to the col- 
oration of the saturated liquid scintillation cocktail during ${ }^{14} \mathrm{C}$ measurement. Thus, purification of the obtained $\mathrm{CO}_{2}$ is necessary for this method.

Wet-oxidation using potassium permanganate produces a gaseous mixture containing mostly $\mathrm{CO}_{2}$ and a few gaseous impurities as oxidation byproducts, which are a function of the soil or sediment composition. Gaseous impurities resulting from the wet-oxidation processes can contribute to the modification of the liquid scintillation cocktail characteristics during the counting time and may therefore give incorrect results for ${ }^{14} \mathrm{C}$ activity from organic carbon in soil and sediments. Thus, purification of the resulting $\mathrm{CO}_{2}$ is also necessary using this method.

The 2 methods give similar results for ${ }^{14} \mathrm{C}$-specific activity (about $0.234 \pm 0.024 \mathrm{~Bq} / \mathrm{g}$ C), values that are expected for surface layer of soil and bottom sediments.

\section{REFERENCES}

Hemmila I, Stahleberg T, Kaihola L. 1994. Bioanalytical Applications of Labelling Technologies. Turku: Wallac Oy. p 60-81.

IAEA (International Atomic Energy Agency). 2004. Management of waste containing tritium and carbon14. Technical Reports Series nr 421. Vienna: IAEA. p 5-37.

Magny J, Baur J. 1962. Pour Comprendre les Analyses de Terre. Toulouse: Centre d'Etude et de Modernisation agricoles Purpan. p 41-2

Mathur SP. 1991. Some comments on loss or accumulation of soil organic matter and their effects on soil quality. In: Mathur SP, Wang C, editors. Soil Quality in the Canadian Context. Technical Bulletin 1991-1E. Ottawa: Agriculture Canada Research Branch. p 50-3.

Schumacher BA. 2002. Methods for the determination of total organic carbon (TOC) in soils and sediments. NCEA-C- 1282, EMASC-001. April 2002. Las Vegas: United States Environmental Protection Agency.

UNSCEAR (United Nations Scientific Committee on the Effects of Atomic Radiation). 2000. United Nations. Sources and Effects of Ionizing Radiation Report to the General Assembly, with Scientific Annexes. New York: United Nations.

Varlam C, Stefanescu I, Varlam M, Popescu I, Faurescu I. 2007. Applying the direct absorption method and LSC for ${ }^{14} \mathrm{C}$ concentration in aqueous samples. Radiocarbon 49(2):281-9.

Vita-Finzi C, Leaney F. 2006. The direct absorption method of ${ }^{14} \mathrm{C}$ assay-historical perspective and future potential. Quaternary Science Reviews 25(9-10): 1073-9. 